\title{
EXAMES DE LABORATÓRIO: SENSIBILIDADE, ESPECIFICIDADE, VALOR PREDITIVO POSITIVO
}

\section{Carolina S. Guimarães}

A evolução do conhecimento médico impõe aos profissionais a necessidade de utilizarem exames subsidiários para confirmar ou afastar uma hipótese diagnóstica, e dos laboratórios de análises clínicas se exige que correspondam a essa expectativa executando exames que estabeleçam com precisão e exatidão um diagnóstico.

Admitindo-se que um laboratório trabalhe em condições ótimas, com reagentes de boa qualidade e dentro dos prazos de validade propostos, técnicas adequadas, pessoal perfeitamente treinado, equipamentos calibrados e controle de qualidade adequado, os desvios que ocorram entre a indagação, expressa pela hipótese diagnóstica, e a confirmação desta, expressa pela positividade no exame laboratorial, decorrerão de questões relativas ao próprio teste.

Os médicos apóiam-se em exames laboratoriais para confirmação da hipótese diagnóstica e sabem que, para tal, precisam contar com testes de alta sensibilidade e alta especificidade.

Estas condições necessárias serão também suficientes? Dito de outro modo, bastaria, para corretamente confirmar uma hipótese diagnóstica, $o$ emprego de um teste de alta sensibilidade e alta especificidade, ou outros fatores poderão ainda influenciar no resultado final?

Sabe-se que sensibilidade é a capacidade que um teste tem de discriminar, dentre os suspeitos de uma patologia, aqueles efetivamente doentes, ou, como definido por Galen e Gambino, 19751, sensibilidade é "a positividade na doença". Para a aferição deste parâmetro toma-se uma amostra de individuos com diagnóstico estabelecido por testes que envolvam a demonstração do agente etiológico, como

\footnotetext{
Laboratório de Soroepidemiologia, Instituto de Medicina Tropical de São Paulo, Departamento de Medicina Preventiva, Faculdade de Medicina da Universidade de São Paulo, Av. Dr. Enéas de Carvalho Aguiar, 470, 05403, São Paulo, SP, Brasil.
}

Recebido para publicação em 9/7/84 no caso de algumas moléstias parasitárias, ou a presença de sinais patognomônicos de uma doença. À porcentagem de positivos resultante chamamos de sensibilidade.

A especificidade, por sua vez, é a capacidade que o mesmo teste tem de ser negativo, em face de uma amostra de individuos que sabidamente não têm a doença em questão e, como definido por Galen e Gambino, 1975', é a "negetividade na saúde". Para a sua aferição deveriam ser tomados os mesmos cuidados descritos anteriormente. A amostra a ser utilizada é de individuos que não apresentem a doença em questão, ausência esta estabelecida por um diagnóstico de certeza.

Estabelecidos estes valores de sensibilidade e de especificidade de um teste sorológico em uma amostra, estendem-se estes valores para uma população em geral, admitindo-se, portanto, que a população se comporte homogeneamente em relação a estes traços.

Em condições ótimas (na vigência de $100 \%$ de sensibilidade e $100 \%$ de especificidade), teriamos então uma de duas respostas, mutuamente exclusivas: o teste é positivo, portanto o individuo tem a doença, ou o teste é negativo, portanto o individuo não tem a doença.

$\mathrm{Na}$ prática, porém, os testes de alta sensibilidade e especificidade não atingem o valor de $100 \%$. Um teste com $99 \%$ de sensibilidade, por exemplo, deixaria de confirmar a hipótese diagnóstica de um individuo dentre 100 efetivamente doentes, conforme a definição acima. Também, um teste com $98 \%$ de especificidade, por exemplo, rotularia como doentes dois entre 100 indivíduos que, efetivamente, não o são.

Aparece aqui, portanto, uma contradição entre os parágrafos iniciais e o anterior. $\mathrm{O}$ individuo que vai a um laboratório clínico está em busca de uma confirmação de hipótese diagnóstica. Trata-se, pois, de um indivíduo pertencente à população em geral, podendo ou não ser alguém verdadeiramente doente. As estimativas de sensibilidade e especificidade do 
Guimarães MCS. Exames de laboratório: sensibilidade, especificidade, valor preditivo positivo. Revista da Sociedade Brasileira de Medicina Tropical 18: 117-120, Abr-Jun, 1985

teste sorológico foram, entretanto, estabelecidas numa amostra, propositadamente viciada, da população à qual pertence aquele individuo. Trata-se, pois, de não mais investigar "a positividade na doença" ou a "negatividade na saúde", porém, dentre o total de positivos, determinar quantos são efetivamente doentes.

Assim, depreende-se que a população em geral se divide em quatro categorias em relação ao traço que se quer investigar: os verdadeiros positivos (individuos que têm a doença e nos quais o teste foi positivo), os verdadeiros negativos (individuos que não têm a doença e nos quais o teste foi negativo), os falsos positivos (individuos que não têm a doença e nos quais o teste foi positivo) e falsos negativos (individuos que têm a doença e nos quais o teste foi negativo).

Num quadro de dupla entrada onde se representasse de um lado a existência ou não da doença e de outro positividade ou negatividade do teste teriamos:

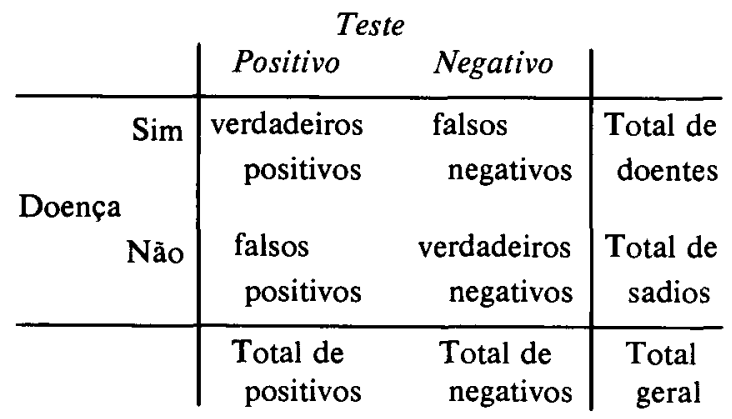

Por este quadro o cálculo da sensibilidade do teste seria:

$$
\text { Sensibilidade }=\frac{\text { verdadeiros positivos }}{\left(\begin{array}{c}
\text { (verdadeiros positivos }+ \text { falsos } \\
\text { negativos) }
\end{array}\right.} \times 100
$$

A soma dos verdadeiros positivos e falsos negativos corresponde ao total de individuos doentes, como se vê pelo quadro.

Correspondentemente, o cálculo da especificidade do teste seria:

$$
\text { Especificidade }=\frac{\text { verdadeiros negativos }}{\left(\begin{array}{c}
\text { (verdadeiros negativos }+ \text { falsos } \\
\text { positivos })
\end{array}\right.} \times 100
$$

e o denominador corresponde à soma dos individuos sadios, como se vê pelo quadro.

As pessoas que vão aos laboratórios de análises clínicas encaminhadas por seus médicos não pertencem, sabidamente, quer à parcela dos doentes quer à parcela dos sadios (pois, se assim fosse, não teriam sido encaminhadas para exames com o intuito de confirmar alguma hipótese diagnóstica). Trata-se, pois, de individuos que fazem parte da população em geral, que se dividirão após o teste em dois grupos, aqueles nos quais o teste foi positivo e aqueles nos quais o teste foi negativo. Segundo o quadro, trata-se de identificar, dentre o total de positivos ao teste, quais os verdadeiros positivos. À qualidade que um teste tem de corretamente identificar tais individuos denomina-se "valor de predição positivo"2.

Este parâmetro será determinado pela identificação dos verdadeiros positivos dentre o total de positivos sorológicos na população (verdadeiros positivos e falsos positivos) e esta estimativa depende da sensibilidade e da especificidade do teste empregado no diagnóstico assim como da prevalência da doença na população.

Calcula-se este parâmetro segundo a fórmula:

$$
\text { VP positivo }=\frac{\text { prevalência } \times \text { sensibilidade }}{\text { prevalência } \times \text { sensibilidade }+} \times 100
$$

e decorre que, quanto mais alta a prevalência menor será o termo (1-prevalência) e maior será o produto (prevalência $\mathrm{x}$ sensibilidade); e quanto mais alta a especificidade menor será o termo ( 1 -especificidade).

Configura-se, então, o fato de que testes com alta sensibilidade e especificidade possam deixar de corretamente confirmar a hipótese diagnóstica se forem utilizados para diagnosticar doença de baixa prevalência numa população, como se pode ver pelos exemplos abaixo.

Admitamos um teste sorológico de sensibilidade $99 \%$ e especificidade $96 \%$ para uma doença que em uma população tenha prevalência de $2 \% \mathrm{e} \mathrm{em}$ outra tenha prevalência de $15 \%$. Pela fórmula, teríamos para a primeira população: valor preditivo positivo igual a $33 \%$, e na segunda população, $81 \%$. Portanto, na primeira população teriamos que, dentre 100 resultados pusitivos, 67 corresponderiam a falsos positivos, levando, portanto, a um diagnóstico errôneo 
Guimarães MCS. Exames de laboratório: sensibilidade, especificidade, valor preditivo positivo. Revista da Sociedade Brasileira de Medicina Tropical 18: 117-120, Abr-Jun, 1985

da doença nestes pacientes. Na segunda população, dentre 100 testes positivos, 19 seriam falsos positivos.

$\mathrm{Na}$ prática, erros tão grosseiros não ocorrem porque os indivíduos que procuram o laboratório para a confirmação da hipótese diagnóstica não se constituem em população não selecionada, porém foram submetidos a uma seleção prévia pelo próprio médico ao estabelecer a hipótese diagnóstica. Desta maneira, nesta amostra a prevalência da doença é mais alta que na população em geral o que condiciona elevação do valor preditivo positivo do teste, como visto no exemplo. Porém, somente em condições de prevalência superior a $50 \%$ é que o valor de predição positivo se aproxima da sensibilidade do teste. Nestes casos, entretanto, a deteç̧ão dos verdadeiros positivos estaria ainda condicionada à capacidade do teste de não resultar em reações positivas dentre indivíduos sadios, ou seja, à sua especificidade.

\section{REFERÊNCIAS BIBLIOGRÁFICAS}

1. Galen RS, Gambino SR. Beyond normality: The predictive value and efficiency of medical diagnosis. J. Wiley \& Sons, New York, 1975.

2. Vecchio TJ. Predictive value of a single diagnostic test in unselected populations. New England Journal of Medicine 274: 1171-1173, 1963. 